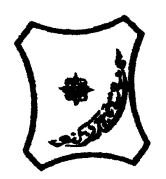

Bayero Journal of Pure and Applied Sciences, 9(1): 223 - 227

Received: June, 2016

Accepted: June, 2016

ISSN $2006-6996$

\title{
HYPOGLYCEMIC AND HYPOLIPIDEMIC EFFECTS OF ETHYL ACETATE LEAF EXTRACT OF Vitex simplicifolia IN ALLOXAN INDUCED DIABETIC WISTER RATS
}

\author{
*Salim, M. A. and Dikko, A.H. \\ Department of Human Physiology, Faculty of Basic Medical Sciences, Bayero University Kano \\ *Corresponding author: zafaralisalimm@gmail.com. Phone: 08033265554
}

\begin{abstract}
The effects of oral administration ethyl acetate leaf extract of Vitex simplicifolia on blood glucose and lipid profile levels of alloxan induced diabetic Wister rats were investigated. The study was conducted with 30 Wister rats, assigned into six groups of five rats each, and daily administration of ethyl acetate leaf extract of Vitex simplicifolia for 21 days was done.; Diabetes mellitus was induced in overnight fasted rats by a single intraperitoneal injection (i.p) of $150 \mathrm{mg} / \mathrm{kg} \mathrm{body}$ weight of Alloxan monohydrate. Group 1 was the normal control group 2 was the diabetic control, group 3 was administered 10mg/kg of glibenclimide (positive control) and groups 4, 5, and 6 were administered 250,500 and $1000 \mathrm{mg} / \mathrm{kg}$ body weight of methanolic of Vitex simplicifolia leaf extracts respectively. There was significant $(p<0.01)$ reduction in fasting blood glucose( $F B G)$ levels relative to their initial values compared to the normal and positive control. The FBG levels decrease by 8,16 and $17 \%$ for 250,500 and $1000 \mathrm{mg} / \mathrm{kg}$ of ethyl acetate extracts respectively. The normal control rats maintained a stable FBG level (102.8 \pm 40.0 to102.68 \pm 4.0$)$ and the positive control decreased by $65 \%$.There were no significant changes $(p<0.01)$ in the levels of total cholesterol(TC), triacylglycerol (TAG), low density lipoprotein - cholesterol(LDL_c) and high density lipoprotein -cholesterol(HDL $-c)$ for the animals administered with the extract compared with the control groups. The result of this study may suggest the possible use of Vitex simplicifolia leaf in the management of hyperglycemia.
\end{abstract}

Keywords: Vitex simplicifolia, hyperglycemic, hypolipidemic

\section{INTRODUCTION}

Diabetes mellitus (DM) refers to a group of common metabolic disorders that share the phenotype of hyperglycaemia and characterized by elevated blood glucose concentration caused by insulin deficiency, often combined with insulin resistance. According to World Health Organization (WHO), there are approximately 171 million diabetics worldwide, this number has double in the last few years and is expected to doubled once again in the year 2025 (Beretta, 2001). Diabetes is a major degenerative disease in the world today, affecting at least 150 million people and having complications which include hypertension, atherosclerosis and microcirculatory disorders (Ogbonnia et al., 2008). The prevalence of diabetes is on the increase globally and in African communities due to the ageing of the population and drastic lifestyle changes accompanying urbanization and westernization (Sobngwi et al., 2001). Also, studies from five West African communities in Nigeria and Ghana have identified genes within populations that create susceptibility to diabetes (Rotimi et al., 2001). The prevalence of diabetes mellitus in Nigeria is $1.9 \%$ with more than 1.5 million cases (IDF, 2015). Hence, it represents a growing burden on health care systems of African countries, most of which already face difficult economic conditions. The disease remains incurable and can only be controlled with drugs; hence, a scrupulous control is needed to help reduce hyperglycemia and the risk of long-term complications, which are known to be the major causes of morbidity and mortality (Rotimi et al., 2010). In Nigeria, information available from the indigenous traditional healers indicates that, a decoction of the chopped stem barks and leaf of Vitex simplicifolia is prepared and taken orally for treatment of diabetes and other disease conditions. The plant extracts have been used as medication for infertility, liver disease, anodyne, stiffness, hypertension, cancer, febrifuge, as tonic galactagogue to aid milk production in lactating mothers, sedative, digestive regulator and treatment of eye troubles, kidney troubles and as supplement for lack of vitamin $A$ and B (Sofowora, 1993; Burkill, 2000).

Although parts of this plant are used by traditional healers of various ailments, there is paucity of scientific study to establish the scientific basis of its use and like many other herbal remedy, there is little or no information about its possible side effects or toxicities.

This study, therefore, was aimed at determining 'the hypoglycemic and hypolipidemic effects of aqueous leaf extract of Vitex simplicifolia on alloxan induced diabetic wister rats. This is important since science requires the validation of drugs by medicinal practitioners and drug regulatory authorities demand that all potential drugs should pass through a rigorous series of study and scrutiny (Abdulrahaman, 2004). 


\section{MATERIALS AND METHODS}

Collection and preparation of plant material

Fresh leaves of Vitex simplicifolia were collected from the botanical garden of Bayero University, Kano with the assistance of Herbarium keeper. The leaves were authenticated in the Department of Biological Sciences, Bayero University Kano (Herbarium number 242). The leaves were dried under room temperature and then grounded using pestle and mortar to a semi powdered form.

\section{Experimental animals}

Thirty (30) adult Wister rats weighing between 160 $240 \mathrm{~g}$ were obtained from the animal house of Department of Physiology, Bayero University, Kano and kept in cages at a room temperature for two (2) weeks to acclimatize and allowed access to food and water ad libitum. The principles of laboratory animal care (NIH publication number 85 - 23, revised, 1985) guidelines were followed.

\section{Plant extract}

Vitex simplicifolia leaves $(500 \mathrm{~g})$ were soaked in 2.5 litres of ethyl acetate at room temperature in a conical flask. The content of the flasks were shaken and the top was covered with aluminium foil and kept at room temperature for $48 \mathrm{~h}$ ( 2 days) after which the extracts were obtained by filtration using a Whatman No 1 filter paper. The extracts were concentrated using vacuum evaporator.

\section{Determination of mean lethal dose '}

The mean lethal dose $\left(L_{50}\right)$ of the ethyl acetate extract was determined in Wister rats (weighing between $150-200 \mathrm{~g}$ ) using the method described by Lorke (1983)

\section{Induction of diabetes mellitus}

Diabetes mellitus was induced in overnight fasted rats by a single intraperitoneal injection (i.p) of $150 \mathrm{mg} / \mathrm{kg}$ body weight of Alloxan monohydrate (Etuk et al., 2010). Hyperglycaemia was confirmed by the elevated blood glucose levels, determined after $72 \mathrm{hrs}$ and then confirmed after $7^{\text {th }}$ day of injection. The rats found with elevated glucose level of $400 \mathrm{mg} / \mathrm{dl}$ and above were used for the study (Masiello et al., 1998).

\section{Experimental design}

A total of thirty (30) Wister rats were used for the study. The rats were divided into Six (6) groups of five (5) each. Extracts were administered orally using $1 \mathrm{ml}$ syringe.

Group 1 - Normal untreated rats (Animal control) Group 2 - Diabetic untreated rats (Diabetic control)
Group 3 - Diabetic rats administered $10 \mathrm{mg} / \mathrm{kg}$ of Glibenclamide (Prasanna et al., 2012)

Groups 4,5 and 6 - Diabetic rats administered 250, 500 and $1000 \mathrm{mg} / \mathrm{kg}$ body weight of ethyl acetate leaf extract of Vitex Simplicifolia respectively.

\section{Sub-chronic studies/ Collection and treatment of samples}

The extracts were reconstituted in distilled water, and administered orally on daily basis by gastric intubation for 21 days. At the end of 21 days, fasting blood glucose level determined. The animals were anaesthetized using chloroform and bled by cardiac puncture $24 \mathrm{hrs}$ after the last treatment. The blood samples were collected in specimen bottles, allowed to clot and the serum separated by centrifugation at 3000rpm for 10 minutes and then subjected to biochemical parameters analysis.

\section{Biochemical Analysis}

The fasting blood glucose levels were determined based on glucose oxidase/peroxidase principle, as described by Clark and Lyons (1962) using a digital glucometer(Accuchek.USA) after fasting the rats for 12 hours. The serum levels of total cholesterol, triacylglycerol and $\mathrm{HDL}-\mathrm{C}$ were determined by enzymatic method described by Stein(1987), while the serum levels of LDL-C was measured according to protocol of Friedewald et al.,(1972).

\section{Phytochemical screening}

Test for anthraquinones was conducted using the method of Felgils(1975) and Test for alkaloids and Terpenes using the method of Sofowora (1979) while Test for saponins,flavonoids and tannins were done using the method of Earl(1961)

\section{Statistical Analysis}

The results obtained are presented as Mean $\underline{ \pm}$ standard error of mean (SEM). A one way analysis of variance (ANOVA) was used for the data analysis. Significant differences between groups were detected in the ANOVA using Bonferini test at $P$ values less than 0.05 and 0.001 .Using SPSS 20 Soft ware package for windows.

\section{RESULTS}

Tables 1 and 2 below indicate the result of acute toxicity studies showing the $\mathrm{LD}_{50}$ of ethyl acetate extract of Vitex simplicifolia leaf is greater than 5000 $\mathrm{mg} / \mathrm{kg}$ body weight.

Table 1: Phase I LD 50 , (Oral) of the ethyl acetate extract of Vitex simplicifolia leaf extract

\begin{tabular}{llll}
\hline Group & No. of Animals & Doses $(\mathrm{g} / \mathrm{Kg})$ & No. of Death \\
\hline 1 & 3 & 10 & 0 \\
2 & 3 & 100 & 0 \\
3 & 3 & 1000 & 0 \\
\hline
\end{tabular}

Table 2: Phase II LD 50 (Oral) of the ethyl acetate extract of Vitex simplicifolia leaf extract

\begin{tabular}{llll}
\hline Group & No. of Animals & Doses $(\mathrm{mg} / \mathrm{Kg})$ & No. of Death \\
\hline 1 & 1 & 1600 & 0 \\
2 & 1 & 2900 & 0 \\
3 & 1 & 5000 & 0 \\
\hline
\end{tabular}


Table 3: Results of phytochemical screening of the ethyl acetate extract of the Vitex simplicifolia leaf

\begin{tabular}{ll} 
Phytochemicals & Qualitative \\
\hline Alkaloids & Present \\
Cardiac glycosides & Present \\
Phenols & Absent \\
Flavonoids & Present \\
Saponins & Present \\
Tannins & Present \\
Steroids & Absent \\
Terpenoids & Absent \\
Phytates & Present \\
Oxalates & Present \\
Cyanates & Present
\end{tabular}

\section{Effects on glycemia}

The effects of daily doses of ethyl acetate leaf extract of Vitex simplicifolia on blood glucose levels of alloxan induced diabetic rats is presented in Table 4.Daily administration of the plant extract to the diabetic rats caused a significant $(p<0.05)$ reduction in fasting blood glucose levels after 21 days. The FBG levels decreased significantly $(\mathrm{p}<0.05)$ by 54,70 and $71 \%$ for 250,500 and $1000 \mathrm{mg} / \mathrm{kg}$ of ethyl acetate leaf extract respectively and the rats administered with 10 $\mathrm{mg} / \mathrm{kg}$ of glibenclimade(reference drug) decrease by $51.5 \%$.

Table 4: Percentage changes in fasting blood glucose of alloxan induced diabetic rats treated with 250,500 and $1000 \mathrm{mg} / \mathrm{kg}$ of ethyl acetate extracts of Vitex Simplicifolia leaf.

\begin{tabular}{lllll}
\hline Group & $\begin{array}{l}\text { Mean Initial } \\
\text { FBG(mg/dl) }\end{array}$ & $\begin{array}{l}\text { Mean Final } \\
\text { FBG(mg/d) }\end{array}$ & $\begin{array}{l}\text { Change } \\
\text { (mg/d) }\end{array}$ & \% Change \\
\hline $\begin{array}{l}\text { Positive control } \\
10 \mathrm{mg} / \mathrm{kg} \mathrm{GCLM}\end{array}$ & $471.7 \pm 20.0$ & $229.0 \pm 20.0$ & $242.7 . \pm 0.00$ & 51.5 \\
Diabetic+250mg/kg ETVSF & $553.0 \pm 21.0$ & $254.0 \pm 2.0$ & $299.0 \pm 19.0$ & $54^{\mathrm{a}}$ \\
Diabetic+500mg/kg ETVSF & $435.0 \pm 16.5$ & $131.0 \pm 2.0$ & $304.0 \pm 14.5$ & $70^{\mathrm{a}}$ \\
Diabetic+1000mg/kg ETVSF & $435.0 \pm 165.5$ & $127.0 \pm 2.0$ & $308.0 \pm 163.5$ & $71^{\mathrm{a}}$ \\
\hline
\end{tabular}

Grp 1: Positive control, Grps 2, 3 and 4 received 250, 500 and 1000mg/kg of extract, respectively. Values are presented as mean \pm standard error of mean. ${ }^{a}=$ significantly different $(p<0.05)$ from the positive control. Key: ETVSF- Ethyl acetate extract of Vitex simplicifolia leaf GCLM- Glibenclimade

\section{Effects on lipid profile}

The effect of daily doses of ethyl acetate leaf extract of Vitex simplicifolia on lipid profile of alloxan induced diabetics rats is presented in Table 5.There was no significant $(p<0.05)$ change in the serum level of total cholestero I(TC), trglyceride (TAG), low density lipoprotein cholesterol (LDL-c) and high density lipoprotein -

Cholesterol ( $\mathrm{HDL}_{-\mathrm{c}}$ ) for the animals administered with the extract compared with the control groups

Table 5: The effect of ethyl acetate extract of Vitex simplicifolia leaf on lipid profile in alloxan induced diabetic rats.

\begin{tabular}{lllll} 
Groups & $\begin{array}{l}\text { Total Chol } \\
(\mathrm{mmol} / \mathrm{l})\end{array}$ & $\begin{array}{l}\text { Triglyceride } \\
(\mathrm{mmol} / \mathrm{l})\end{array}$ & $\begin{array}{c}\mathrm{HDL} \\
(\mathrm{mmol} / \mathrm{l})\end{array}$ & $\begin{array}{c}\mathrm{LDL} \\
(\mathrm{mmol} / \mathrm{l})\end{array}$ \\
\hline 1 & $0.24 \pm 0.01$ & $0.12 \pm 0.05$ & $0.20 \pm 0.03$ & $0.02 \pm 0.03$ \\
2 & $0.27 \pm 0.01$ & $0.11 \pm 0.03$ & $0.12 \pm 0.02$ & $0.10 \pm 0.01$ \\
3 & $0.14 \pm 0.11$ & $0.08 \pm 0.03$ & $0.13 \pm 0.06$ & $0.07 \pm 0.04$ \\
4 & $0.12 \pm 0.01$ & $0.06 \pm 0.012$ & $0.06 \pm 0.012$ & $0.21 \pm 0.02$ \\
5 & $0.12 \pm 0 \mathrm{E}-7$ & $0.11 \pm 0.001$ & $0.04 \pm 0.01$ & $0.21 \pm 0.02$ \\
6 & $0.07 \pm 0.05$ & $0.13 \pm 0.04$ & $0.09 \pm 0.01$ & $0.23 \pm 0.02$ \\
\hline
\end{tabular}

Grp 1: Normal control, Grp 2: Negative control, Grp 3: Positive control, Grps 4, 5 and 6 received 250,500 and $1000 \mathrm{mg} / \mathrm{kg}$ of extract, respectively. Total chol $=$ Total cholesterol. Values are presented as mean \pm standard error of mean. ${ }^{a}=$ significantly different $(p<0.05)$ from the Normal control, ${ }^{b}=$ significantly different $(p<0.05)$ from the Negative control.

\section{DISCUSSION}

The result of acute toxicity study indicated that the $\mathrm{LD}_{50}$ of the methanolic leaf extract of Vitex simplicifolia is greater that $5000 \mathrm{mg} / \mathrm{kg}$ body weight.
Thus, the non-lethal effects produced with the high dose of this extract are an indication that the leaf extracts of Vitex simplicifolia is relatively safe on acute oral exposure. 
It can therefore be concluded that Vitex simplicifolia leaf extract is non-toxic, which is in agreement with the report of Abdelmagid (2014) on essential oil of the leaves of Vitex simplicifolia and with Bruce (1987), American Society for Testing and Materials (1987), Aditya and Ravi (2014),Kingsley et al (2014) and Ravichandra et al(2014), that any chemical substance with $\mathrm{LD}_{50}$ estimate greater than $3000-5000 \mathrm{mg} / \mathrm{kg}$ (oral route) could be considered of low toxicity and safe.

The use of plants in the treatment of disease and in particular diabetes mellitus is as old as man (Sofowora, 1993).This is because plants have shown to contain some potent bioactive compounds with antidiabetic properties (Tanko et al., 2013). In this study, diabetes established on the basis of fasting blood glucose concentration in the alloxan treated rats on $5^{\text {th }}$ day of the experimental period formed the baseline values (Table 4). The result indicated that daily oral administration of reference drug and the ethyl acetate extracts of Vitex simplicifolia for 21 days show significant reduction in fasting blood glucose showing 54, 70 and $71 \%$ at 250,500 and $1000 \mathrm{mg} / \mathrm{kg}$ respectively. However extracts showed more potency then glibenclamide (reference drug). The observed anti diabetic effect of the ethyl acetate leaf extracts of Vitex simplicifolia is an indication that the extracts contain bioactive phytochemicals with potent antidiabetic property. Anti diabetic activity of Vitex simplicifolia have never been reported to our knowledge, however, the aqueous and methanolic extracts of Vitex doniana had been reported to have potent anti diabetic properties more potent than the reference drug (glibenclamide) by Nwogo et al., (2013), Ibrahim et al.., 2014) and Muhammed et al (2015) reported similar hypoglyceamic activity of chloroform and $\mathrm{n}$ - hexane fractions of Ceiba pentandra leaf. The hypoglycemic action of medicinal plants may be of the following mechanism; inhibition of renal glucose reabsorption, enhanced secretion of insulin from B-cells of the pancreas, increased tissue uptake of glucose by enhancement of insulin sensitivity, regeneration/repair of the B-cells and/or

\section{REFERENCES}

Abdel majid, O., Noya $\mathrm{S}$, Jean $\mathrm{K}$, Sylvin $\mathrm{O}$ and Innocent P G (2014).Acute toxicity and irritancy of the essential oil of the leaves of Vitex simplicifolia Oliv.(Verbenaceae) in Bourkinafaso,Journal of Pharmacology and Toxicology.9(1):62-67

Abdulrahaman, F.I (1992).Studies in natural products chemistry. The moraceae in African traditional medicine and management of psychiatry in Borno State. M.Sc Thesis. University of Maiduguri. Maiduguri.

Aditya,K and Ravi,K (2014).Toxicity studies of combined extracts of Vitex pubescence, Vitex penducularis and Vitex agnucastus, Indian Journal of Research in pharmacy and Biotechnology,2(2):1109 -1113

American Society for testing and Materials. (1987). Standard test method for estimating acute oral toxicity. OECD 425:1-8 prevention of oxidative stress that is possibly involve in pancreatic B-cells destruction as reported for other antidiabetic plants (Kim et al., 2006; Okpe et al., 2012).

In this study the ethyl acetate leaf extracts of Vitex simplicifolia showed no significant effect on lipid profile of the experimental animals. This correspond with the reported study on methanolic and aqueous extract of Vitex donniana by Okpe et al., (2012).The ethylacetate extract of Vitex simplicifolia have no significant effect on the level of total cholesterol and low density lipoprotein. These observations may be attributed to the gut intra luminal interactive effect of saponin. Saponins are known anti nutritional factors which reduce the uptake of certain nutrients including glucose and lipid especially cholesterol at the gut through intra-lumena physicochemical interaction. Hence saponins have been reported to have hypocholestrolemic effect (Price et al., 1987). Saponin, among other secondary metabolites is found to be present in the leaves of Vitex simplicifolia in this study (Table 3) and corresponds with reported presence of saponin in Vitex donniana (Eghareuba et al., 2010).

The low concentration of cholesterol may have contributed to the observed non - significant high serum HDL - cholesterol in the experimental animals. About $30 \%$ of blood cholesterol is carried in the form of HDL and it is hypothesized that HDL cholesterol can remove cholesterol from antheroma within arteries and transport it back to the liver. HDL - cholesterol protect against cardiovascular disease (Okpe et al., 2012). The observed non - significant ( $P>0.05$ ) increase in HDL - cholesterol concentration after administration of the extracts $(250,500$ and $1000 \mathrm{mg} / \mathrm{kg} \mathrm{bw}$ ) indicates that the extract does not have HDL - cholesterol boosting effect and it does not also have significant $(P>0.05) \quad L D L$ - cholesterol lowering effect at these concentrations in induced diabetic experimental animals. In conclusion, the ethyl acetate leaf extract of Vitex simplicifolia is observed to have potent hypoglyceamic activity on alloxan induced diabetic wister rats.

Bruce, R.D (1987). A Confirmatory Study of up-anddown Method of Acute Oral Toxicity Testing. Fundamental Applied Toxicology. 8: 97-100.

Burkill HM (2000). Useful Plants of Tropical West Africa.2nd ed.. Royal Botanic Garden Keiv. 272-275

Earl J.K (1961) Chemical composition of plant tissues.Biochemists Handbook.Redwood Press London

Etuk, E (2010).Animal models for studying diabetes mellitus. Agriculture and Biology Journal of North America. issn 2151-7517.http://www scihub.org/ABJNA.

Felgils F. (1975). Anthraquinone Ascobic acid ,Stop test in organic analysis. Elservier Press, Amsterdam 
Ibrahim, S., Okpe, O., Njoku G.C and Ndidi U.S (2014).Antihyperglycemic and antihyperlipidemic effect of aqueous and ethanolic leaf extracts of Vitex doniana in streptozotocin - induced diabetic rats, Research Journal of Medicinal Plants 8(4):178 -186

International Diabetes Federation(IDF),(2015). Diabetes Atlas. 4th edn. The economicimpact of diabetes.http://www.diabetes atlas.org/content/economic impact of diabetes. Accessed on February 4,2010.

Kingsley .C, Patrick I, Edidiong A. O and Orish E (2014) Evaluation of acute and sub-chronic toxicities of Vensestin Cleansers: a polyherbal supplement in female Wistar Albino rats, Journal of Applied Pharmaceutical Science; 4 (06): 074-078.

Lorke D.A (1983). A new approach to practical acute toxicity testing. ArchToxico/54:275 - 87

Muhammad H.L, Busari M.B, Okonkwo U.S and Abdullah A.S (2015).Biochemical effects of ceiba pentandra leaf used in the folkloric treatment of diabetes,British Journal of Pharmaceutical Research.6(1):44 -60

National Institute of Health (1985): Principles of Animal Care. National Institute of Health, Bethesda, Md.Pp 85-23

Nwogo A.O,Kalu M K,Uchechukwu $\mathrm{O}$ and Glory $\mathrm{O}$ (2013).Hypoglycemic effects of Aquesous and Methanolic Leaf extracts of Vitex doniana on alloxan induced diabetic albino rats. J.Med.Sci.,13(8):700 -707

Ogbonnia SO, Odimegwu JI and Enwuru VN (2008). Evaluation of hypoglycemic and hypolipidemic effects of ethanolic extracts of Treculia africana Decne and Bryophyllumpinnatum Lam. and their mixture onstreptozotocin (STZ) - induced diabetic rats. Afr. J. Biotechnol., 7(15):2535-2539.

Okpe, O, Abdullahi, S A., Nkeonye, O, Ilechukwu C., Nweke,O and Ihuoma O. (2012).
Hypoglycemic and Hypolipedimiceffects of aqueous and ehanalolic leaf extracts of Vitex doniana in normoglycemic Albino rats. Global Advance Reaserch journal of Microbiology,1(10)173-179.

Prasanna R, Sivakumar. V and Riyazullah. M. S (2012) Antidiabetic Potential of Aqueous and Ethanol Leaf Extracts of Vitex negundo. International Journal of Pharmacognosy and Phytochemical Research; 4(2); 38-40

Ravichandran V, Deivam S, Anbu1, and Reeta R (2014) Acute and sub-acute toxicity studies of ethanolic poly-herbal extract in mice. International Journal of Pharmacology \& Toxicology, 4(2): 80-87

Rotimi SO, Olayiwola I, Ademuyiwa O and Adamson I (2010).Inability of legumes to reverse diabetic-induced nephropathy in rats despite improvement in blood glucose and antioxidant status.J. Med. Food, 13:163-9.

Sobngwi E, Mauvais-Jarvis F, Vexiau P and Gautier JF (2001). Diabetes in Africans: epidemiology and clinical specificities. Diabetes Metab (Paris), 27: 628-34.

Sofowora, A. (1993).Medicinal Plants and Traditional Medicine in Africa.2ndEdn.,Spectrum Books, Nigeria, ISBN13:9789782462190,pp142-144

Tanko, Y, .N.H.Sada, K.A.Mohammed, Jimoh, M.Yerima and A.Mohammed (2013). Effect of ethanolic extract of Carallumadaizialli on serum electrolylytes levels on fructoseinduced diabetes in wistar rats Ann.Res. 4:157-161

W.H.O, (2003). World Health Organization guidelines on good agricultural and collection practices(GACP) for medicinal plants, p 80

World Health Organization (WHO). (2003). United Nations Fact Sheet No. 134, on Traditional Medicine. 